Brain, Behavior and Evolution
Brain Behav Evol 2018;92:32-46

DOI: $10.1159 / 000490341$
Received: April 18, 2018

Returned for revision: May 16, 2018

Accepted after revision: May 23, 2018

Published online: October 31, 2018

\title{
How Not to Be Turned into a Zombie
}

\author{
Kenneth C. Catania \\ Department of Biological Sciences, Vanderbilt University, Nashville, TN, USA
}

\section{Keywords}

Cockroach · Evolution · Insects · Mechanosensation ·

Wasps · Parasitoid - Defense - Escape response

\begin{abstract}
The emerald jewel wasp (Ampulex compressa) is renowned for its ability to zombify the American cockroach (Periplaneta americana) with a sting to the brain. When the venom takes effect, the cockroach becomes passive and can be led by its antenna into a hole, where the wasp deposits an egg and then seals the exit with debris. The cockroach has the ability to walk, run, or fly if properly stimulated, but it does not try to escape as it is slowly eaten alive by the developing wasp larva. Although the composition and effects of the wasp's venom have been investigated, no studies have detailed how cockroaches might prevent this grim fate. Here it is shown that many cockroaches deter wasps with a vigorous defense. Successful cockroaches elevated their bodies, bringing their neck out of reach, and kicked at the wasp with their spiny hind legs, often striking the wasp's head multiple times. Failing this, the elevated, "on-guard" position allowed cockroaches to detect and evade the wasp's lunging attack. If grasped, the cockroaches parried the stinger with their legs, used a "stiff-arm" defense to hold back the stinger, and could stab at, and dislodge, the wasp with tibial spines. Last-
\end{abstract}

ly, cockroaches bit at the abdomen of wasps delivering the brain sting. An aggressive defense from the outset was most successful. Thus, for a cockroach not to become a zombie, the best strategy is: be vigilant, protect your throat, and strike repeatedly at the head of the attacker.

(c) 2018 The Author(s)

Published by S. Karger AG, Basel

\section{Introduction}

The "zombification" of the American cockroach (Periplaneta americana) by the emerald jewel wasp (Ampulex compressa) stands out as one of the most remarkable and well-studied examples of host behavioral manipulation by a parasitoid [Williams, 1942; Piek et al., 1984; Veltman and Wilhelm, 1991; Richardson and Paul, 1993; Fouad et al., 1996; Weisel-Eichler and Libersat, 2002; Haspel and Libersat, 2003; Haspel et al., 2003; Libersat, 2003; Gincel et al., 2004; Gal et al., 2005, 2014; Keasar et al., 2006; Moore et al., 2006; Libersat and Gal, 2007, 2013, 2014; Gal and Libersat, 2008, 2010a, b; Libersat et al., 2009; Fox et al., 2009; Kaiser and Libersat, 2015]. In order to reproduce, the emerald jewel wasp must somehow lead its much larger victim to a chamber, glue an egg to the cockroach in just the right spot, and seal the chamber with debris [Williams, 1942]. The host, which could dig its way

\begin{tabular}{|c|c|}
\hline KARGER & $\begin{array}{l}\text { (c) } 2018 \text { The Author(s) } \\
\text { Published by S. Karger AG, Basel }\end{array}$ \\
\hline $\begin{array}{l}\text { E-Mail karger@karger.com } \\
\text { www.karger.com/bbe }\end{array}$ & $\begin{array}{l}\text { This article is licensed under the Creative Commons Attribution- } \\
\text { NonCommercial-NoDerivatives } 4.0 \text { International License (CC BY- } \\
\text { NC-ND) (http://www.karger.com/Services/OpenAccessLicense). } \\
\text { Usage and distribution for commercial purposes as well as any dis- } \\
\text { tribution of modified material requires written permission. }\end{array}$ \\
\hline
\end{tabular}

Dr. Kenneth C. Catania

Department of Biological Sciences, Vanderbilt University

VU Station B, Box 35-1634

Nashville, TN 37235 (USA)

E-Mail ken.catania@vanderbilt.edu 

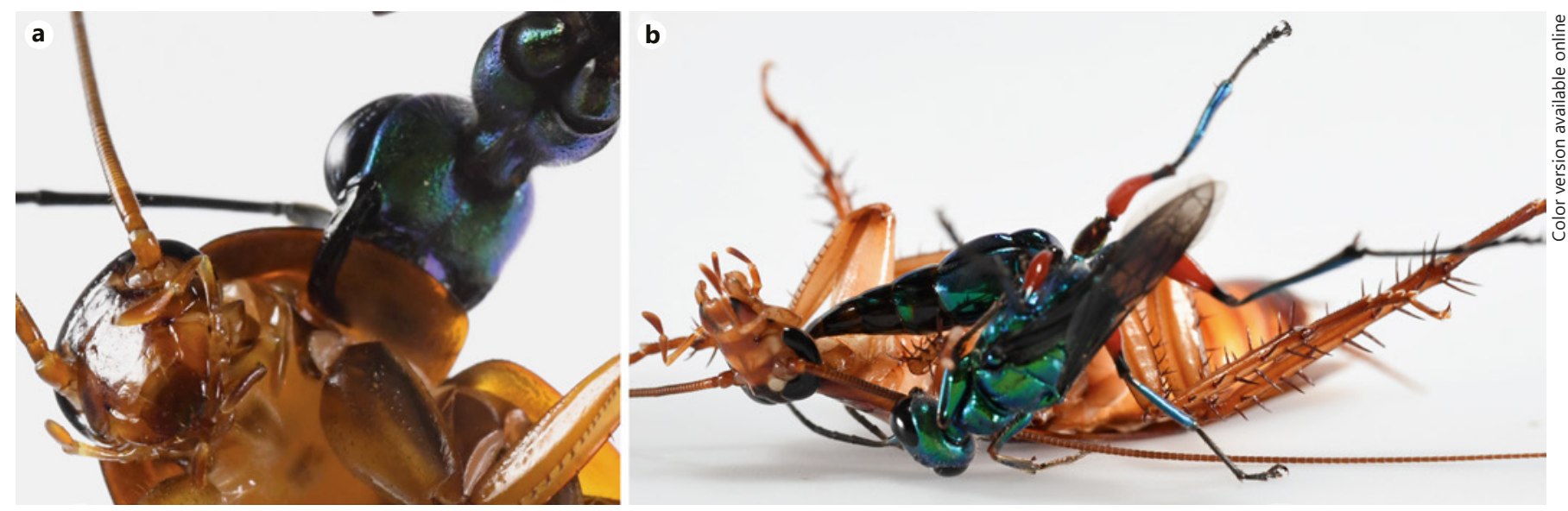

Fig. 1. A jewel wasp (Ampulex compressa) attacking an American cockroach (Periplaneta Americana). a Jewel wasps begin their attack by firmly grasping the plate-like pronotum of the cockroach with their mandibles. b After having paralyzed the front legs with a first sting into the first thoracic ganglion (not shown), the second sting is made into the head and brain of the cockroach.

out, must instead remain passively in the chamber while it is slowly eaten alive by the developing wasp larva.

Of course, the cockroach does not start out as a willing participant in this macabre ritual. The wasp subdues the cockroach with a stereotyped attack [Williams, 1942; Piek et al., 1984; Veltman and Wilhelm, 1991]. The wasp begins by grasping the cockroach just behind the head with its curved mandibles (holding fast to the edge of the pronotum; Fig. 1) and then delivers two stings. The first sting is directed through the soft membranes of the lower thorax and thence directly at the part of the cockroach's nerve cord that controls the front legs (the prothoracic ganglion), into which venom is delivered [Haspel and Libersat, 2003]. This first sting causes temporary paralysis of the front legs and is immediately followed by a second sting penetrating through the soft connective tissues of the neck and directly into the brain [Haspel et al., 2003]. This second sting causes $30 \mathrm{~min}$ of grooming [Weisel-Eichler et al., 1999] followed by long-lasting pacification, but not paralysis, of the cockroach. After the brain sting, the cockroach can walk, run, fly, or swim if properly stimulated, but for weeks it does not engage in these behaviors [Piek et al., 1984; Weisel-Eichler and Libersat, 2002; Libersat and Gal, 2007]. It is said to have lost its free will, and hence is often referred to as a zombie. Presumably the wasp's unusual strategy evolved because it cannot carry a large, paralyzed cockroach. Instead it needs a walking but behaviorally pliable food source for its young that can be led, like a dog on a leash [Libersat and Gal, 2007], to a distant chamber where it can be safely entombed with the wasp's egg.
The specificity of the jewel wasp's attack, targeting areas of the cockroach's nervous system, requires much greater precision than many parasitoid stings that deliver venom systemically into the host hemolymph. Similarly, the effect of the venom, which causes sequential changes in the cockroach's behavior, is very specific compared to the effect of many parasitoid venoms that cause total paralysis [Libersat and Gal, 2007]. Yet, despite the efficacy of the jewel wasp's venom, the attack is not without risk, nor is it sure to succeed. A number of investigators have reported defensive behaviors by cockroaches approached by a jewel wasp. Williams [1942] described an intense struggle between wasp and roach during which the latter parried with its legs and sometimes bit and killed the wasp. Richardson and Paul [1993] reported that wasps were often damaged during the attack, leading to their death. Fox et al. [2009] observed cockroaches preventing wasp attacks entirely by elevating their bodies while kicking and biting at the wasps.

In addition to these defensive behaviors reported specifically during jewel wasp attacks, the more general escape behaviors of the American cockroach have been a longstanding focus of neuroethological study, most thoroughly investigated for airborne cues generated by predators [Camhi and Tom, 1978; Ritzmann, 1984; Camhi, 1988; Ritzmann et al., 1991; Nye and Ritzmann, 1992; Ritzmann, 1993] but also for mechanosensory stimuli applied to the body and antennae [Comer and Dowd, 1993; Comer et al., 1994; Schaefer et al., 1994; Ye et al., 2003]. These and other features of the American cockroach (e.g., 
giant neurons and large fibers) have made it a convenient species for both research and teaching [Oakley and Schafer, 1978; Camhi, 1984].

The jewel wasp's attack therefore presents a special opportunity. It provides a motivated predator that specifically targets its prey, and thus can be used to reliably and repeatedly test and examine the cockroach's defensive repertoire. It seems likely that cockroach defenses have evolved in response to a wide range of different predators. On the other hand, every jewel wasp is "of cockroach born" - the result of a successful attack on a cockroach [Williams, 1942]. As a result, the selective pressure for the wasp to overcome the specific defenses of the cockroach could hardly be higher. We may therefore learn about the evolution of the wasp's unusual attack strategy by better understanding the behavior of its target.

In this study, the interactions between cockroaches and jewel wasps were investigated by high-speed video to determine the range of defensive behaviors used by cockroaches and to document the wasp's attack strategy. The aim was to add new detail to an already rich area of neuroethology.

\section{Materials and Methods}

Emerald jewel wasps (A. compressa) were obtained from Hawaii and maintained and bred in an approved insect containment facility (facility \#3226) under permit No. P526P-17-01368. Lights were cycled on a 12/12-h light/dark regimen. The room temperature was approximately $23^{\circ} \mathrm{C}$. Supplementary lighting raised the temperature of the BioQuip dorms to $25^{\circ} \mathrm{C}$. Parasitized cockroaches were transferred to ventilated $50-\mathrm{mL}$ tubes (Celltreat 229479 Bio-Reaction Tube; Daigger Scientific Inc.) and placed into a separate Plexiglas chamber. Supplementary radiant heat lamps and a water chamber maintained the humidity above $50 \%$ in the chamber at a temperature between 25 and $28^{\circ} \mathrm{C}$. Hatched wasps were sexed, and males were housed with $3-5$ per bug dorm. Females were first introduced into the male cages and given $48 \mathrm{~h}$ to mate. After mating, each female was maintained individually in a 1452 BioQuip Bug Dorm (BioQuip Inc., Rancho Dominguez, CA, USA) and provided free access to water through a wet sponge along with sucrose on a separate wet filter pad. Cockroaches $(P$. americana) were obtained from either a colony at Vanderbilt or ordered as adults from Carolina Biological (Carolina Biological Supply Company, Burlington, NC, USA). Up to 25 females were maintained at a time for several years - individual adults typically lived several months.

High-speed macro videos of interactions between wasps and cockroaches were recorded at 1,000 frames per second with a MotionXtra NX7S1 color camera (IDT Inc., Tallahassee, FL, USA) with a 28-105 zoom lens and with two RPS Studio CooLED 100 RS-5610, or with two 120W Intelligent LED Luminaire strobe lights (Dynamic Imaging, Brentwood, TN, USA) using a circular buffer to capture events that occurred prior to manual triggering.
Note that this paradigm results in an arbitrary time "zero" indicated on the supplementary Movies S0-S8 (for all online suppl. material, see www.karger.com/doi/10.1159/000490341) and the Figures. For high-magnification trials, the high-speed camera was connected to a Wild M400 dissecting microscope. In some trials, cockroaches climbed onto the upper, clear plastic top of the container, and were approached by the wasp from below. The videos were exported as JPEGs and then opened in QuickTime Player 7 Pro (Apple Inc.), and the sequences were exported as QuickTime movies. Schematic figures were produced in Adobe Illustrator (Adobe Systems Inc.), and slow-motion behavioral sequences were illustrated by importing selected frames into the document using the "place" command. Photos of animal behavior were made with a Nikon D5 SLR (Nikon Inc., Melville, NY, USA).

For the real-time behavioral examination of cockroach defenses and wasp attacks, data on 37 trials were collected using a $22-\mathrm{cm}$ diameter (3.5-cm-depth) circular chamber made from plastic and covered with a clear section of Plexiglas. For 18 additional realtime behavioral trials, a second rectangular chamber measuring $10 \times 16 \times 7 \mathrm{~cm}(\mathrm{~L} \times \mathrm{W} \times \mathrm{H})$ was used. The behavior was filmed with a Nikon D5 camera in video mode. Lighting was provided by two RPS Studio CooLED 100 RS-5610 lights.

Jewel wasps had successfully attacked and entombed at least one cockroach prior to filming, although these may have been subadult cockroaches. For the behavior trials, adult cockroaches of either sex were used. Each cockroach was inspected to ensure that all limbs were intact before the trials; those with damaged legs were not used. It should be noted that comparatively large cockroaches were used in this study (see Figures) because these were most likely to exhibit defense behaviors (no subadults were used).

A cockroach was introduced into the chamber 2 min prior to the wasp. The wasp was transferred from the home cage to the filming arena in a $50-\mathrm{mL}$ tube and was allowed to enter through a small hole in the Plexiglas cover. For the purposes of this study, a cockroach was scored as having successfully defended itself against an attacking wasp if it had not been stung after $3 \mathrm{~min}$. Trials during which the wasp did not stalk the cockroach were not included. In all of the real-time behavioral trials, sting 1 by the wasp was followed by sting 2 , and hence such trials were scored as a failed defense.

For the purposes of this study, high-speed video was used to document the range of behaviors exhibited by wasps and cockroaches, but these short time segments were not amenable to scoring relative frequencies of behaviors. Statistics $\left(\chi^{2}\right.$ test, Wilcoxon rank sums) were calculated with the JPM software program version 14 (SAS).

\section{Results}

Keasar et al. [2006] have outlined the sequence of behaviors exhibited by the jewel wasp from the first encounter with a cockroach to successful egg deposition and entombment. They suggest 10 stages that include (1) host targeting, (2) thorax sting, (3) head sting, (4) host probing, (5) antennal cutting, (6) feeding from host, (7) nest exploration, (8) host insertion into the nest, (9) oviposi- 
tion, and (10) collection of debris to stopper the nest opening. From start to finish, this sequence often takes well over $1 \mathrm{~h}$ to complete. The present study focuses on a different side of the interaction: on the behaviors of the cockroach during the wasp's attack. The most relevant defensive behaviors occur between host targeting and the sting in the head. It is most informative to initially consider the results of the present study in two categories: (1) cockroaches that defended themselves while being stalked, and (2) those that put up no initial defense.

\section{No Defense}

Many cockroaches were apparently taken by surprise by an aggressive jewel wasp. Others became aware of the attacking wasp, as evidenced by evasive turns and attempted escape, but they exhibited no defense while being stalked. Running was not considered a defense in the context of the present study, as the cockroaches were by necessity contained within a comparatively small space (but see Discussion). In the absence of any defensive behaviors, wasps were typically able to grasp the pronotum and rapidly position the abdomen for sting 1 . In 5 such trials with 5 different wasps, after the pronotum had been grasped by the wasp, the stinger was in position for sting 1 in half a second (mean $512 \mathrm{~ms}$ ). Note that the latter data represent examples from high-speed video and are not included in the real-time data analysis (see Materials and Methods). Online supplementary Movie S0 shows an example of the pronotum grasp in slow motion, with rapid stinger placement despite vigorous, but futile, escape attempts by the cockroach (online suppl. Movies S6-S8 show real-time encounters).

In 55 real-time video trials, roughly half of the cockroaches $(n=28)$ exhibited no initial defensive behaviors in response to the stalking wasp. Of those 28 cockroaches, all were grasped by the pronotum, and 24 were stung (both sting 1 and sting 2). The mean time from the onset of stalking to sting 1 in these cases was $11 \mathrm{~s}$. In 4 of the "no-defense" trials, the cockroaches were able to subsequently escape from the wasp's hold on the pronotum (see next section on Cockroach Defenses for escape strategies) and were not stung within the next $3 \mathrm{~min}$ (therefore categorized as successful defense). Thus only $14 \%$ of the cockroaches that did not put up an initial defense avoided being stung during the first $3 \mathrm{~min}$.

\section{Cockroach Defenses}

The next section describes the commonly observed defensive behaviors that were exhibited while cockroaches were stalked and after they had been grasped by the pro- notum. The chronological series of events that was most often observed is first outlined. The behaviors described below are not meant to represent an exhaustive list of all possibilities, and there are obvious limitations inherent in a laboratory setting. With these caveats in mind, defensive behaviors included (in order of occurrence): (1) stiltstanding, (2) kicking, (3) a contact-triggered escape response, (4) an escape response to pronotum grasp, (5) raking, stabbing, and a "stiff-arm" defense with leg spines, and (6) biting.

In 27 of the 55 real-time video trials, the cockroach began defending itself as the wasp stalked, as indicated by the stilt-standing posture, usually accompanied by kicks (14 of 31 females and 13 of 24 males defended themselves). In these cases, 10 ( 7 females and 3 males) of the 27 cockroaches were stung within the first $3 \mathrm{~min}$, and hence were categorized as a failed defense. Still, it took successful wasps a mean time of $127 \mathrm{~s}$ to sting the 10 cockroaches that defended themselves. This was significantly longer than with the 24 wasps putting up no defense ( $p=$ 0.0002; Wilcoxon rank-sum $\chi^{2}$ approximation). On the other hand, 17 of the 27 cockroaches $(63 \%)$ that defended themselves were able to deter the wasp, or keep it at bay, for the first $3 \mathrm{~min}$, and were thus characterized as a successful defense. There was a significant difference in wasp success when attacking defending and nondefending cockroaches (two-tailed $\chi^{2}$ test, $p=0.0002$ ). Details are described below.

\section{Stilt-Standing}

Once alerted to the presence of a wasp, the cockroaches often assumed a stilt-standing defensive posture [Bell and Sams, 1973]. During this behavior, the cockroach elevated its body by bringing the legs underneath it and usually maintained close to a right angle between the femur and the tibia of the mid- and hind legs (Fig. 2). From this "on-guard" position, the cockroach made many postural adjustments depending on the movements of the attacker. Figure $2 \mathrm{~b}$ illustrates a common variant of the stilt-standing posture during which the cockroach rocked its body over the legs on the side opposite the approaching wasp and simultaneously angled its body away from the wasp. Often, the cockroach then rotated its body to position the attacker to the rear (Fig. 2c). Figure $2 \mathrm{~d}$ shows a typical, nondefensive cockroach body posture, which can be contrasted with stilt-standing (Fig. 2e, f). The latter stance provided a number of advantages that presumably generalize to a range of predators. For example, the cockroach's body (and pronotum, the wasp's target) was elevated and distant from the attacker, which was instead 

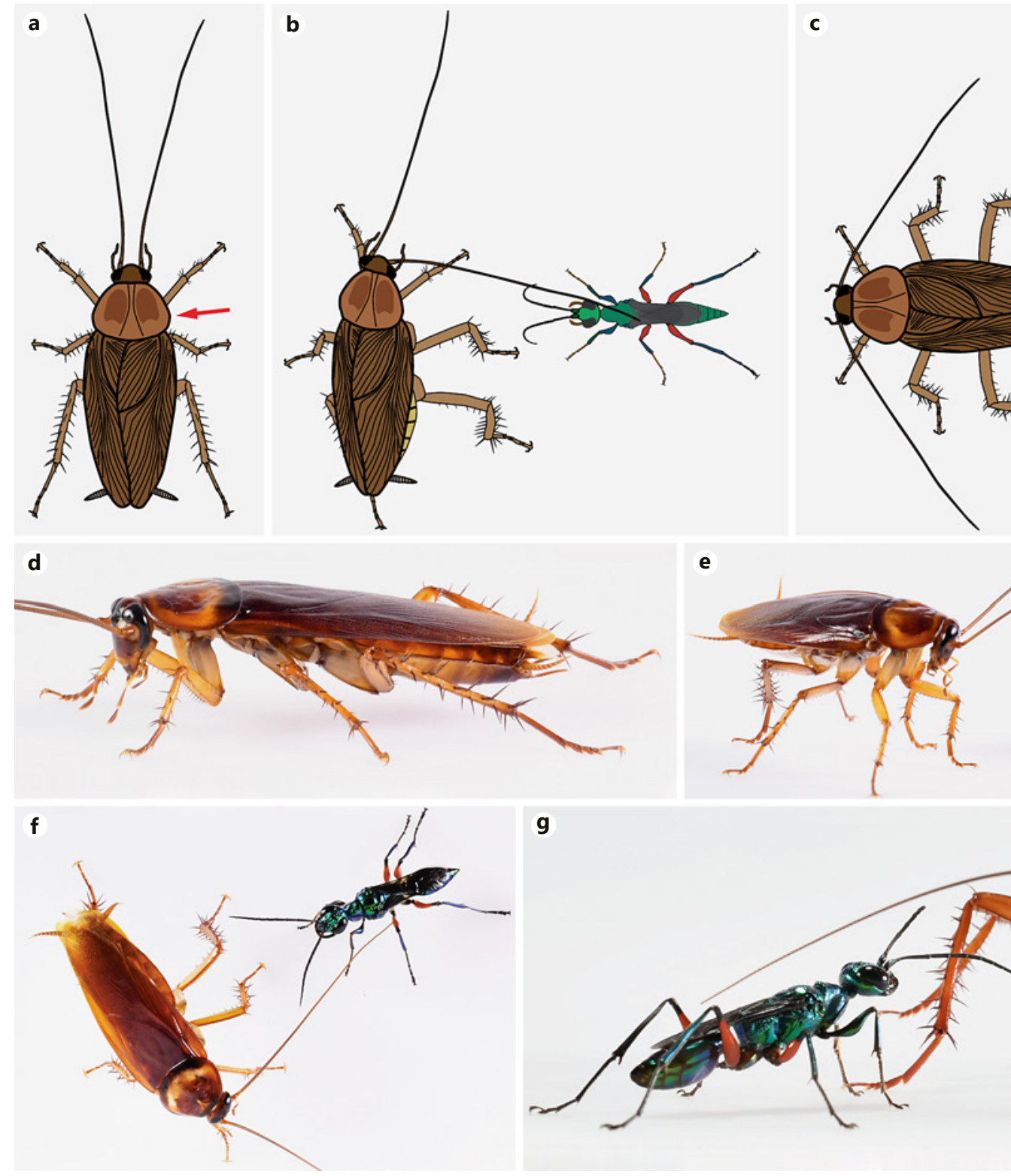
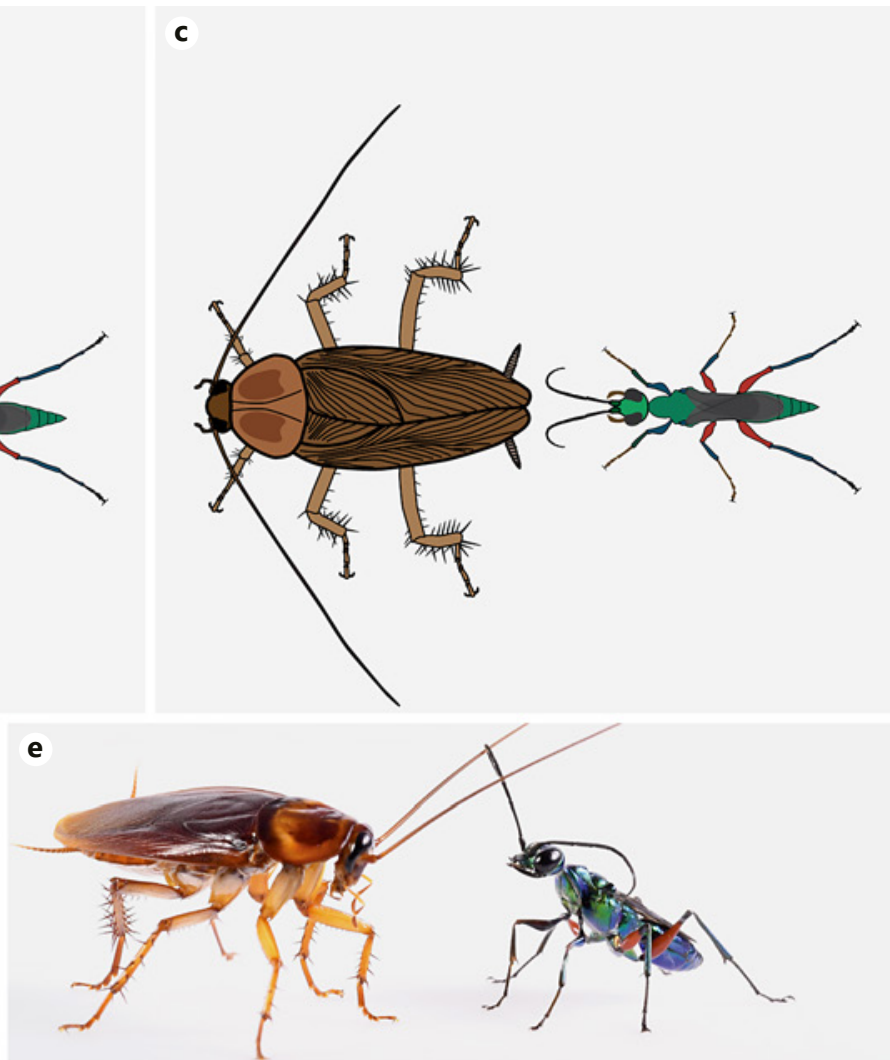

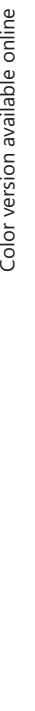

Fig. 2. The stilt-standing defensive posture of the cockroach. a Schematized dorsal view of a typical cockroach posture, with the wasp's target (the pronotum) indicated with a red arrow. b Schematized stilt-standing posture with the legs and one antenna oriented toward the approaching wasp. c The cockroaches commonly turned away from the wasp, allowing for a kicking defense with the powerful hind legs. $\mathbf{d}$ Side view of a cockroach in a typical pos-

faced with a phalanx of tibial spines. The closest antenna was generally oriented toward the threat, often tracking the movements of the wasp through direct contact (Fig. 2f, g). But perhaps most importantly, the stilt-standing position allowed the cockroach's hind legs to move through a wide arc during defensive kicking at the wasp. ture. e Side view of stilt-standing in response to a wasp, illustrating the elevation of the cockroach's body. f Stilt-standing while orienting the legs and one antenna toward the cockroach. g Stilt-standing after turning to position the wasp behind, illustrating the cockroach's body angled away from the wasp. In this stance, the pronotum is distant and raised away from the wasp.

\section{Kicking Defense}

Although some apparently defensive extensions of the forelegs and midlegs were made, the hind legs were exclusively used for powerful and stereotyped kicks that often sent the wasp careening into the walls of the filming chamber - or, in larger arenas, threw the wasp many cen- 
a

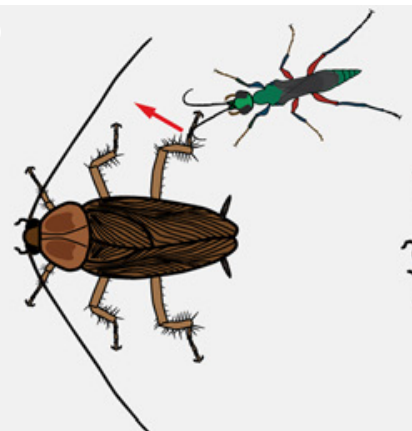

b
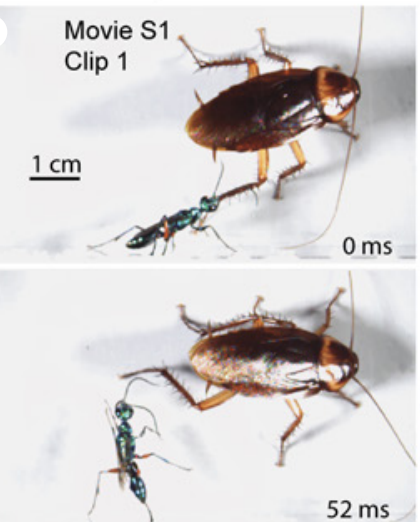

$52 \mathrm{~ms}$

c Movie S1

Clip 2

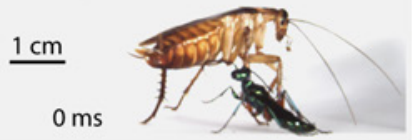

$183 \mathrm{~ms}$
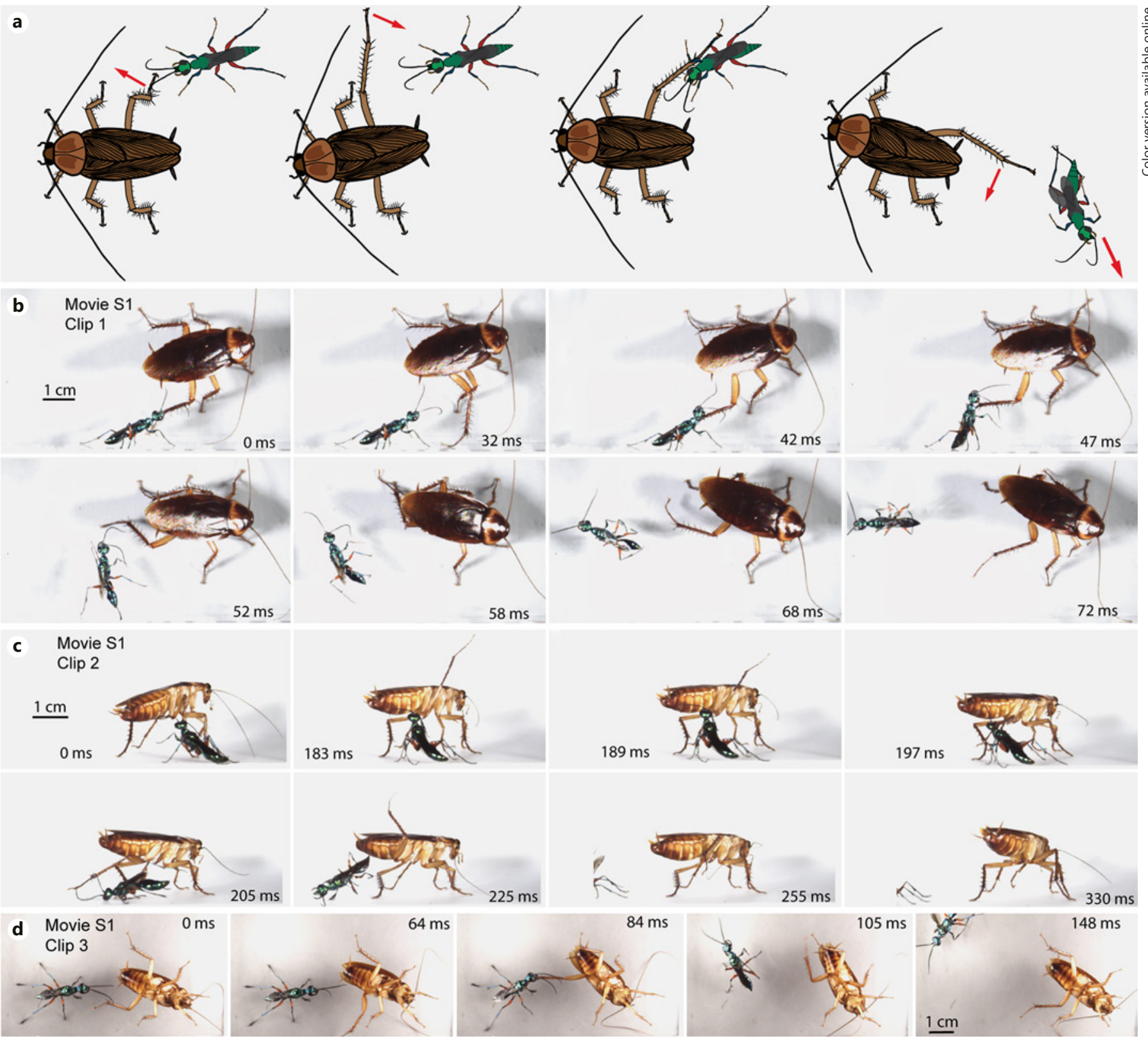

Fig. 3. Kicking defense by the cockroach. a Schematized sequence of movements (red arrows) during the kick. The hind leg is raised and extended rostrally, and then swept back through the target, often projecting the wasp many centimeters away. b Frames captured from a video showing a defensive kick by a cockroach that impacts the wasp on the head and propels it away (top view). c Frames captured from a video showing a kick with a similar result (side view). Note the dorsal extension of the leg during the windup phase. d Ventral view of a defensive kick, with the cockroach holding on to the top of the chamber. timeters away (Fig. 3). The kicks had a "windup" phase during which the tibia was usually extended at the knee joint as the entire hind leg was drawn forward and up; then the hind leg swept down and back through the target with the inner or ventral surface of the tibia impacting (online suppl. Movie S1). The movement was reminiscent of a baseball bat swing, in that it required a windup phase, a swing phase, and considerable follow-through with the entire body of the cockroach. This can be appreciated, for example, in clip 4 of online supplementary Movie S1. In this trial, there was no interference with the windup (as may have occurred in clip 1, when the wall of the chamber 

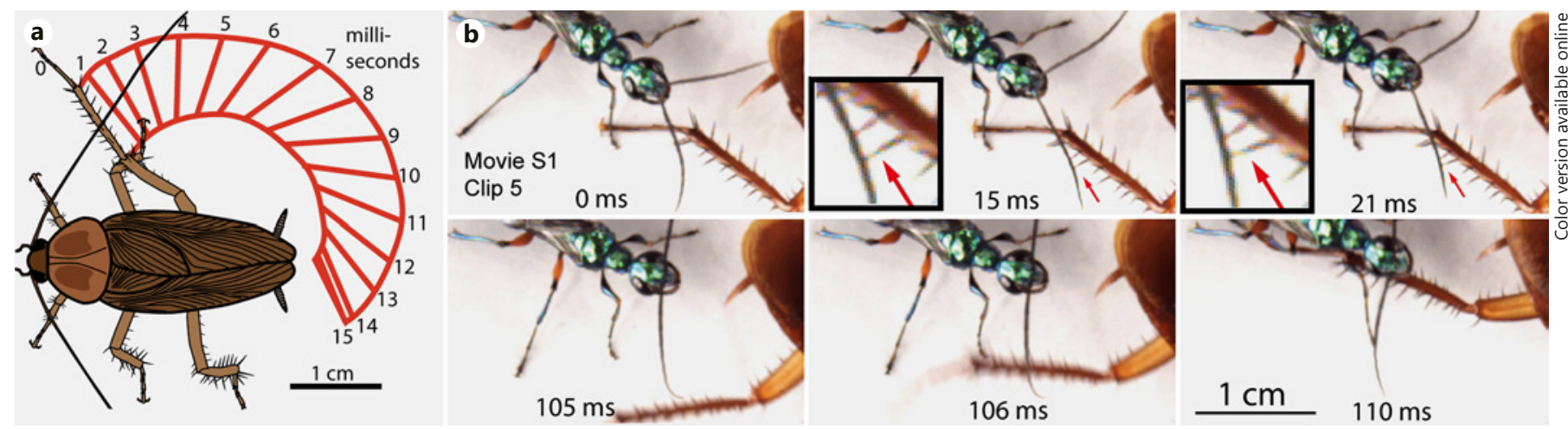

Fig. 4. Timing and elicitation of a kick. a Schematic illustration of the hind leg's position every millisecond for the swing phase of a kick. The positions were taken from the trial shown in clip 4 of online supplementary Movie S1. Note that the movement of the cockroach's body is not illustrated; rather, the leg's positions are relative to the initial body position. $\mathbf{b}$ Close view of a kick as filmed with a camera attached to a microscope. Just prior to the kick, the wasp's antenna deflects a single tibial spine (insets; red arrows). See clip 5 of online supplementary Movie S1 for the full trial. was contacted) and no interference with the swing upon impact with the wasp's head. The swing phase of the kick is illustrated schematically in Figure 4a, which shows the position of the tibia every millisecond during the swing, relative to the starting position of the cockroach's body. The duration of the swing was typical (e.g., online suppl. Movie S1).

In all observed cases of defensive kicking, there was direct contact between the wasp and the cockroach prior to the kick (online suppl. Movie S1). This suggests that kicks are mainly elicited through mechanical cues, as has been reported for crickets defending themselves from digger wasps [Gnatzy and Heusslein, 1986; Hustert and Gnatzy, 1995]. Strikes to the wasp's head followed naturally from the probing action of the wasp's antennae; the wasp leads with its head, and the wasp's antennae usually seemed to be the eliciting mechanical stimulus. In addition to responding with an immediate kick following contact, the cockroaches often probed briefly with the distal hind leg before initiating a kick, apparently to gage the location of their target (online suppl. Movie S1, clips 2, 4, 6, and 7). This appeared to be a form of active sensing with the leg.

When the cockroach's leg was stationary prior to the kick, it was often possible to see a specific contact point, and sometimes even the deflection of a single tibial spine, with a location and timing appropriate for eliciting the kick. For example, Figure 4b illustrates a trial during which the high-speed camera was attached to a microscope, and a single tibial spine can be seen deflected by the antenna of the approaching wasp just prior to the kick (online suppl. Movie S1, clip 5).
Clip 6 of online supplementary Movie S1 shows the cockroach using its antenna to probe - followed by a probing motion with the hind leg, then contact of the cockroach's abdomen with the wasp's antenna - before the kick. Clips 7 and 8 show a wider view and longer encounters. In clip 7, the cockroach made two probing motions with its hind leg. In each case, the wasp's antenna was contacted by the cockroach's leg, followed immediately by a kick.

Finally, the role of mechanosensation in eliciting the kick was further supported by the serendipitous results shown in clip 9 of online supplementary Movie S1. In this trial, the wasp was kicked away by the cockroach, but the claws of the wasp's right midleg caught the cockroach's antenna. As the wasp was projected away, the antenna was pulled backwards, eventually contacting the distal tibia of the cockroach's hind leg as it returned from the kick. The cockroach then (uncharacteristically) initiated a second full kick, although there was no stimulus other than touch by its own displaced antenna.

\section{Escape Responses}

In the trials described above, the cockroach kicked after somewhat tentative probing contact made by the approaching wasp with its legs or antennae. After being thrown back from a kick, many wasps quickly returned to their stalking behavior and were eventually able to progress to the next stage of attack, which consisted of a sudden lunge at the cockroach's pronotum. When the cockroaches were in their stilt-standing posture, their antennae and legs were favorably positioned such that the 

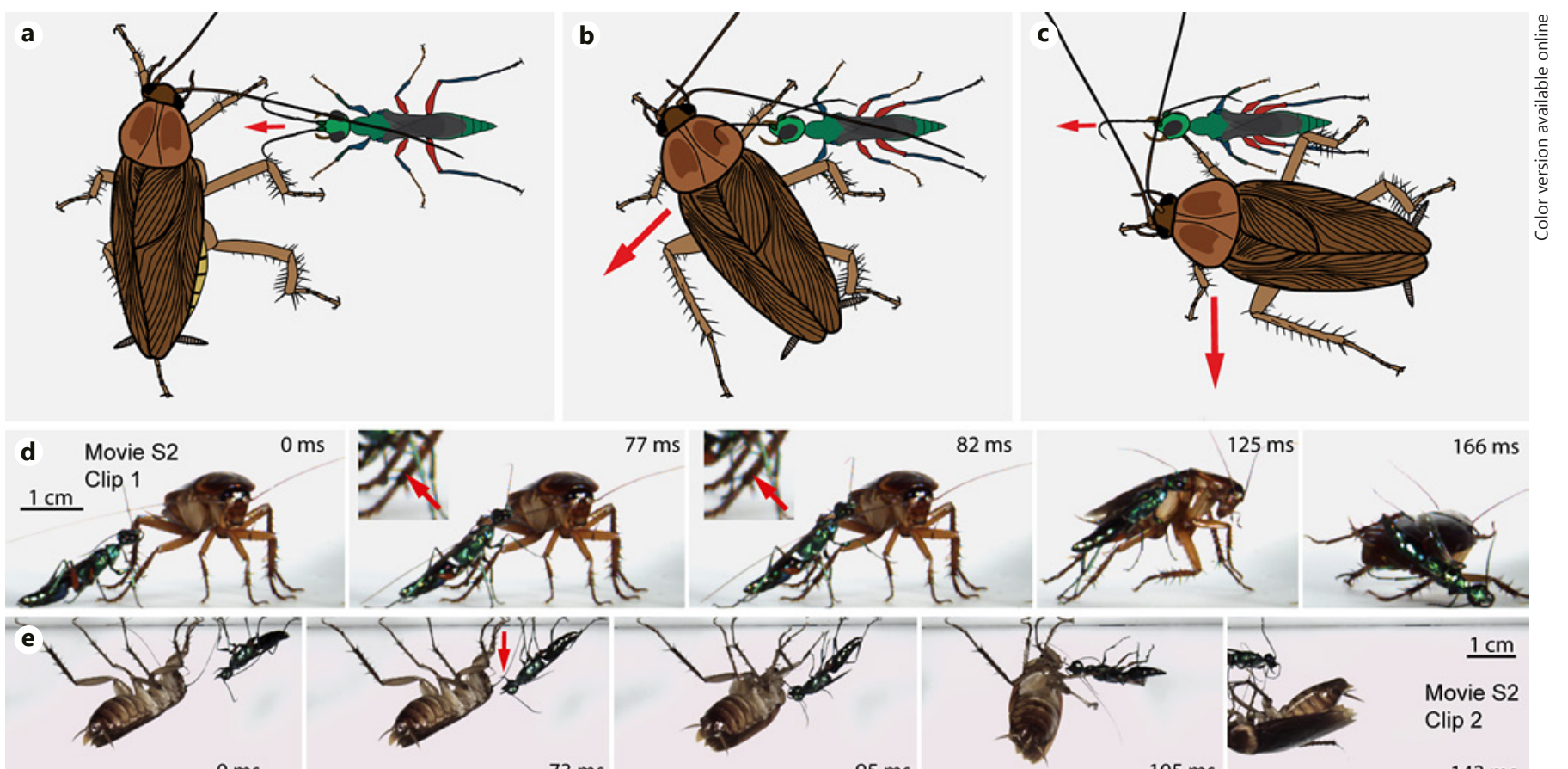

$0 \mathrm{~ms}$
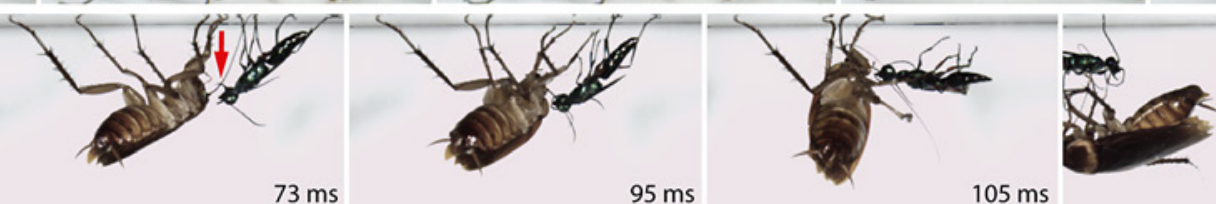

$1 \mathrm{~cm}$
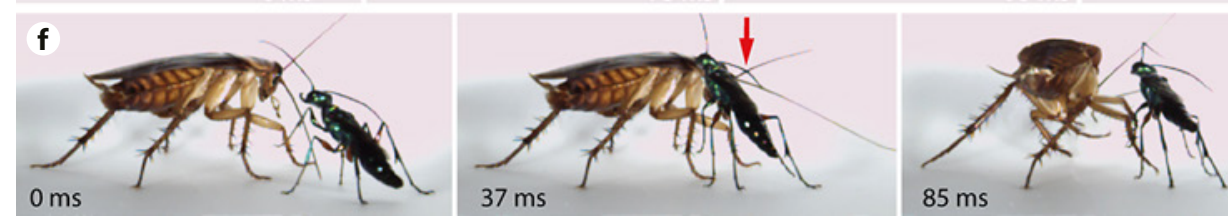

$105 \mathrm{~ms}$

Movie S2

Clip 2

$143 \mathrm{~ms}$

Fig. 5. Escape responses elicited by a wasp's lunge. a-c Schematic illustration of a cockroach's escape, starting from a stilt-standing position (movements shown with red arrows). As the wasp lunges for the pronotum, contact is often made with one of the cockroach's legs or antennae, followed by a short-latency turn by the cockroach. d Frames captured from a video showing a wasp's lunge for the pronotum of a stilt-standing cockroach, and simultaneously deflecting a tibial spine of one of the cockroach's legs (insets; red arrows). The subsequent escape response moves the pronotum with only milliseconds to spare. See online supplementary Movie S2, clip 1. e A wasp lunges for the pronotum of a stiltstanding cockroach but hits the antenna with its mandibles (red arrow). Note that the roach and the wasp are holding on to the upper surface of the chamber. See online supplementary Movie S2, clip 2. f A wasp lunges for the pronotum of a stilt-standing cockroach but hits the antenna with its antenna (red arrow), followed by a short-latency turn by the cockroach. wasps often contacted either a foreleg's tibial spine or the ipsilateral antenna during the lunge. In apparent response, some cockroaches initiated a successful, shortlatency escape that consisted of a rapid turn away from the wasp (Fig. $5 \mathrm{a}-\mathrm{C}$ ), resulting in a failed pronotum grasp by the wasp.

Online supplementary Movie S2 clip 1 shows an example of a wasp contacting the leg during its attack (Fig. 5d). As the wasp lunged, its foreleg rapidly depressed and then released a single tibial spine (red arrow in online suppl. Movie S2, clip 1; inset in Fig. 5d). Just before the wasp reached the pronotum, the cockroach turned away in a classic escape response. In other cases, the antenna was contacted during the attack, with a similar result. For example, in clip 2 of online supplementary Movie S2, the wasp's jaws impacted the antenna prior to reaching the pronotum, followed by a successful escape response (Fig. 5e). Clip 3 of online supplementary Movie S2 shows a similar trial during which the wasp's antenna contacted the cockroach's antenna during the lunge for the pronotum. In this case, the escape response had clearly begun prior to contact between the wasp's jaws and the cockroach's pronotum. In clip 4 of online supplementary Movie S2 (red arrow), the wasp leapt upward but contacted the cockroach's antenna with its leg. Although the escape response in the latter case occurred after contact with the pronotum, the short latency suggests the antennal contact may have triggered, or contributed to, the escape response. 

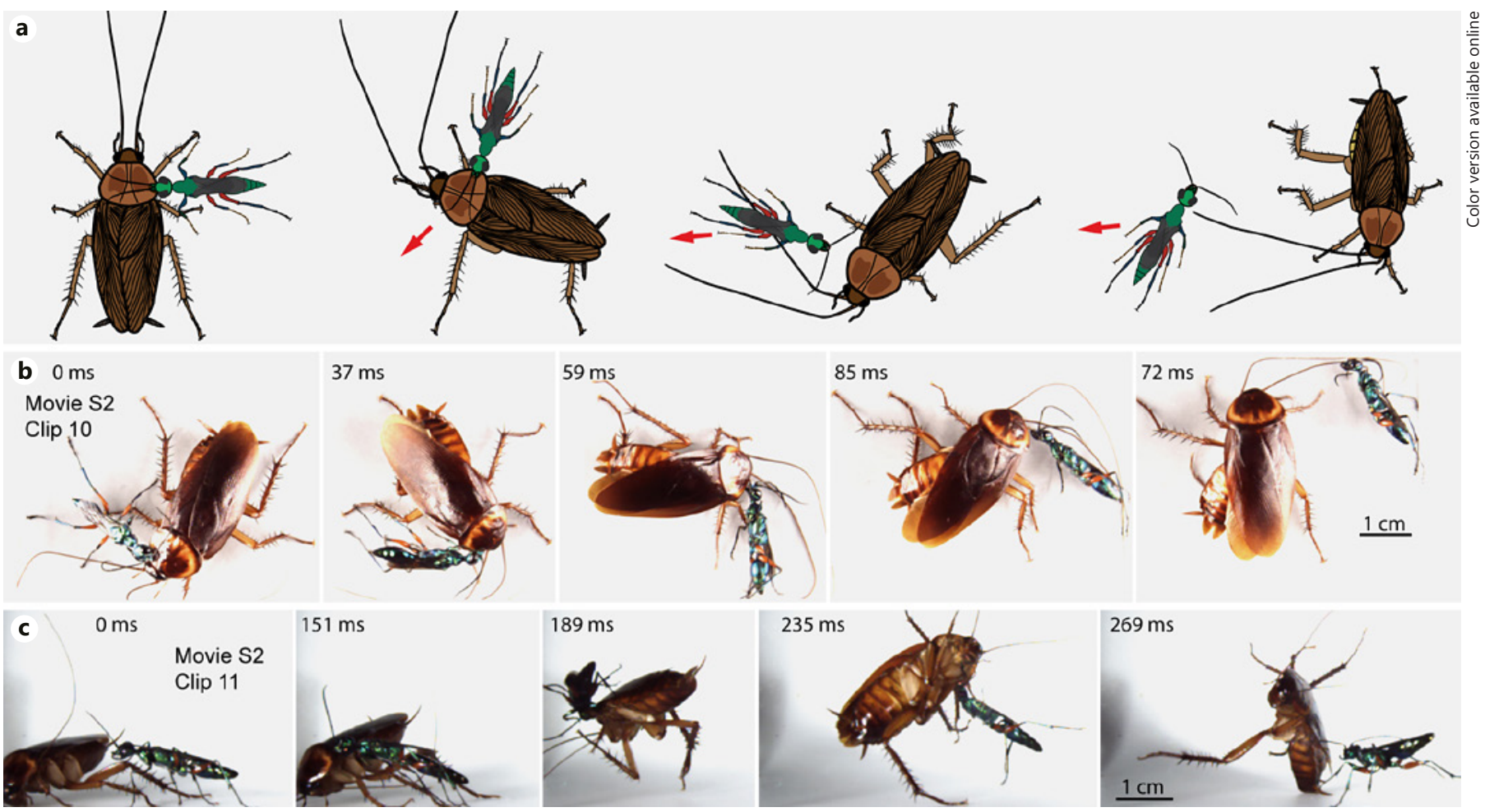

Fig. 6. Escape responses elicited by a wasp's grasp to the pronotum. a Schematic illustration of successful escape after a pronotum grasp. If not already elicited, an escape response at this point was always triggered. The rapid turn sometimes dislodged the wasp (red arrows) but more often failed. b Frames captured from a vid- eo showing a wasp's dislodgment by a sudden turn. See online supplementary Movie S2, clip 10. c Frames captured from a video showing a wasp's dislodgment from turning. See online supplementary Movie S2, clip 11.
The trials above were highlighted because they included short-latency escapes that suggested the cockroach was responding to observable mechanical stimulation that occurred during the wasp's lunge, prior to the wasp's contact with the pronotum. Clearly, such escape responses have greater efficacy than those in response to closure of the wasp's jaws on the pronotum, at which time they are often too late. This interpretation is strengthened by the more common observation of a different class of escape responses: those that occurred, with a slight delay, after the wasp's jaws had closed on the pronotum (Fig. 6). Online supplementary Movie S2 clips 5-9 illustrate such escape responses, where no prior contact was evident during the wasp's lunge. If not already triggered, an escape response was always triggered when the wasp's jaws closed on the pronotum.

\section{Defense with Tibial Spines}

Once the wasp has secured a hold on its pronotum, the cockroach still has a number of defenses at its dis- posal. The most common behavior, observed in nearly every encounter that reached this stage, was the vigorous use of the spiny legs in a raking defense against the wasp. The utility of this defense was most obvious when the cockroach simply dislodged the wasp. Figure 7a illustrates this behavior schematically, showing the use of the midleg. In general, the cockroach pushed the leg against the wasp, securely lodging the spines against the wasp's body and legs, and then simultaneously turned while moving its leg caudally. However, there were many variations, and the cockroaches used different legs, or combinations of legs, depending on the position of the wasp. Figure $7 \mathrm{~b}$ and $\mathrm{c}$ illustrate 2 examples. Online supplementary Movie S3 (clips 1-10) shows these 2 trials in full form, in addition to 8 other trials during which the cockroaches successfully dislodged the wasps using this strategy.

Even when the wasp was not dislodged, the legs - and the spiny tibiae in particular - could be used to lift the wasp's abdomen (and stinger) away from its target, or to
40

Brain Behav Evol 2018;92:32-46 DOI: $10.1159 / 000490341$
Catania 


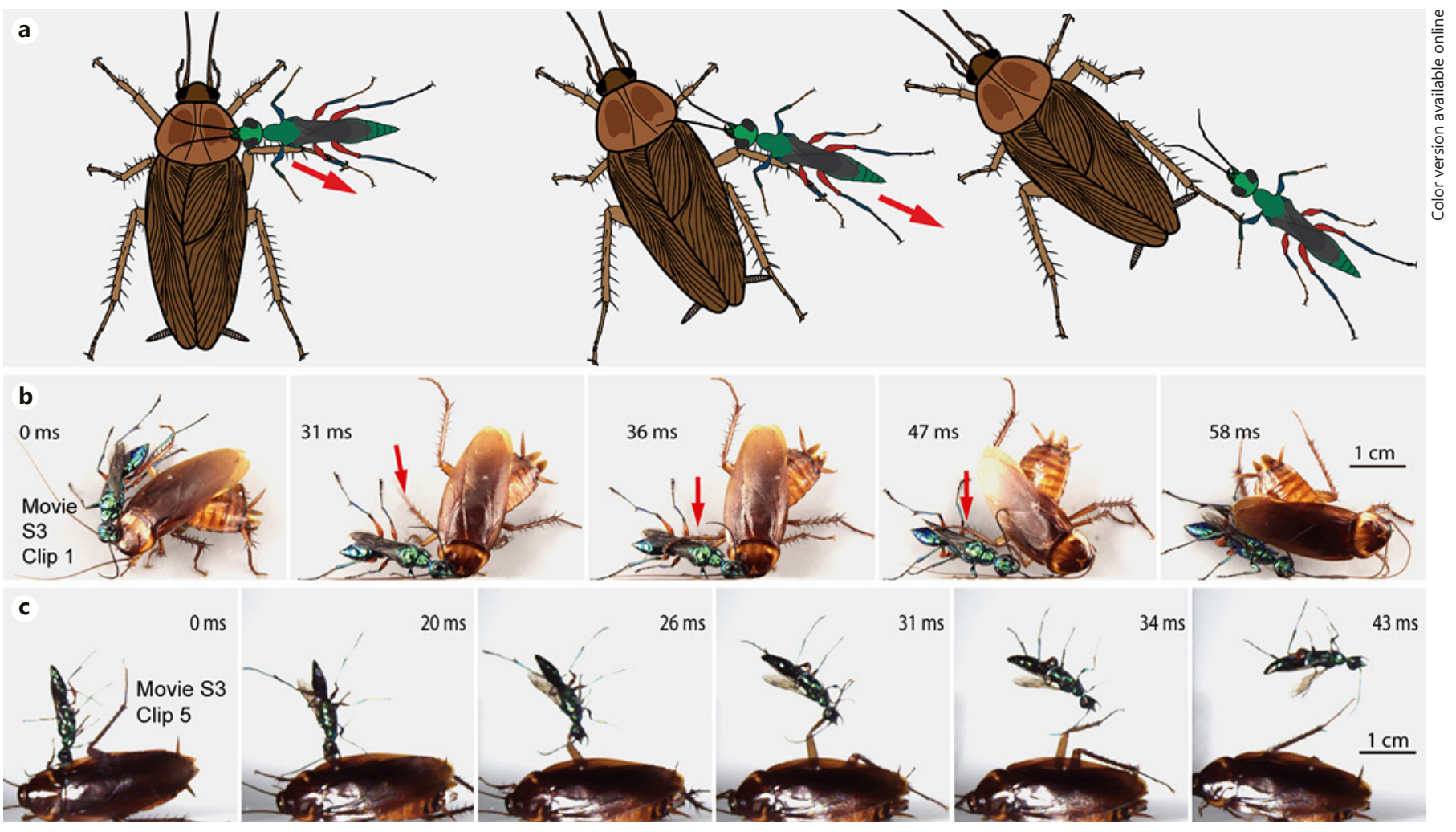

Fig. 7. Use of tibial spines to dislodge a wasp. a Schematic illustration of a cockroach using the tibial spines on the midleg to dislodge a grasping wasp. The leg is drawn forward, pressed against the wasp, and then drawn backwards, while the body is simultaneously rotated away (red arrows). b Frames captured from a video showing the use of tibial spines (red arrows) to dislodge a wasp. See online supplementary Movie S3, clip 1. c Frames captured from a video showing the use of tibial spines to dislodge a wasp. See online supplementary Movie S3, clip 5. hold it at bay using what might be called a "stiff-arm" defense. Figure 8a illustrates this behavior schematically, showing the extended midleg and hind leg. Figure $8 \mathrm{~b}$ shows an example of this behavior in a frame captured from a high-speed video (see online suppl. Movie S4, clip 1). Often the wasp subsequently moved its abdomen to circumvent this obstruction. However, it was also possible for the tibial spines of the cockroach's leg to lodge between some of the wasp's abdominal segments during the struggle. An example is shown in Figure 8c. The involvement of the front legs in this defensive behavior (e.g., online suppl. Movie S5, clips 1 and 2) suggests the importance of sting 1 for the wasp, which would then allow for sting 2 , into the brain, to happen without such interference.

Finally, it should be noted that the tibial spines on the cockroach's hindleg are much longer than those on the forelegs, and they could potentially pierce the soft tissue between the wasp's abdominal segments. This possibility was explored with a dead wasp and a cockroach's leg; in these circumstances, the tibial spines of the roach's leg could be easily inserted between the wasp's abdominal segments, piercing and deeply penetrating the underlying connective tissue. How often this might occur in nature is unknown, but it might help explain why wasps usually abort attacks when they grasp too far caudally, allowing the cockroach to effectively rake with its hind legs.

\section{Biting}

Although sting 1 temporarily paralyzes the front legs [Haspel et al., 2003], the cockroach can still bite. Moreover, depending on the particular position of the wasp's grasp, while delivering sting 2 , its abdomen must often be positioned close to the jaws. Figure $8 \mathrm{~d}$ illustrates such an outcome with a frame captured from a high-speed video with the camera attached to a microscope. Online supplementary Movie S5 clip 4 shows this encounter, 


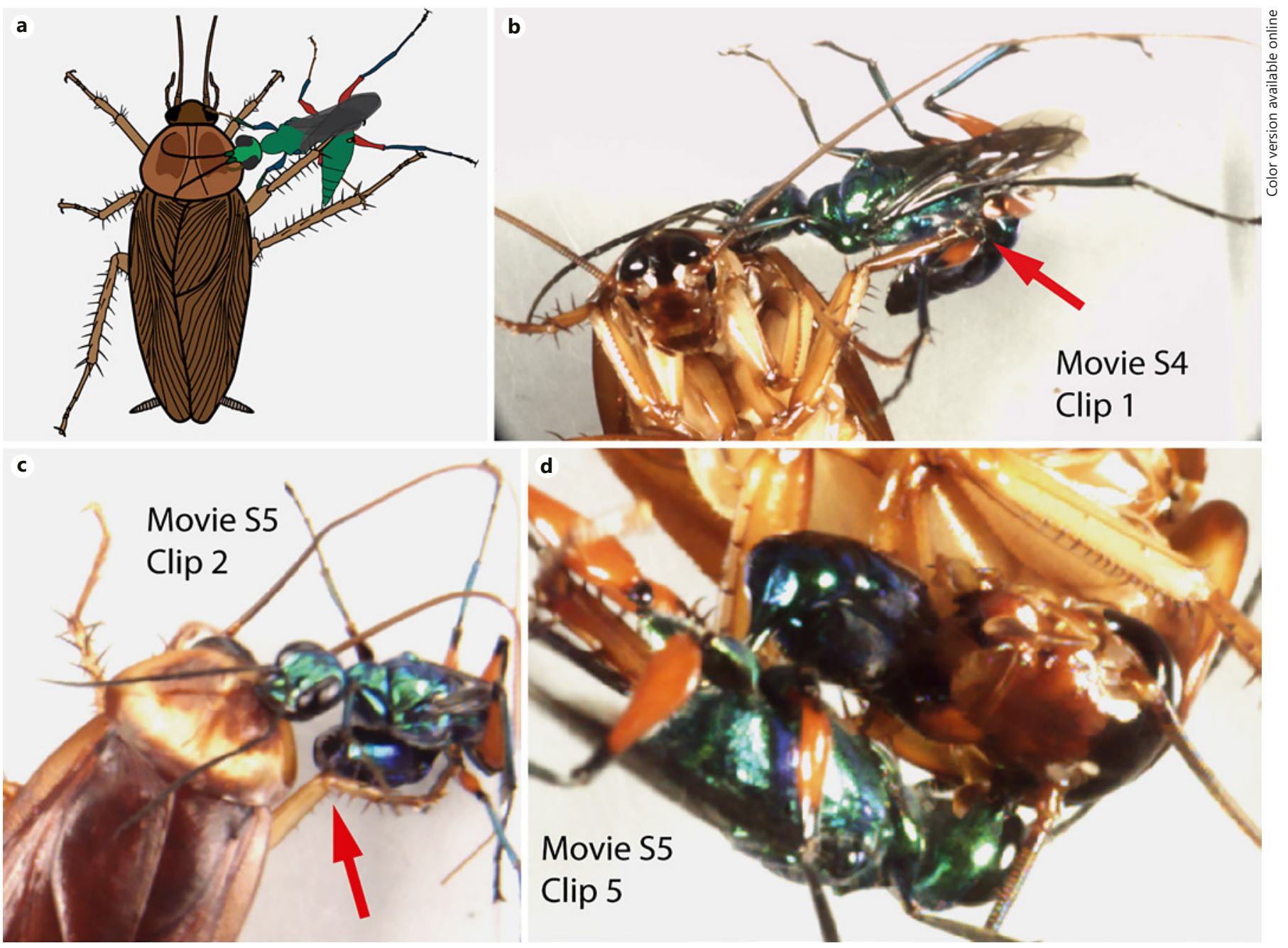

Fig. 8. Stiff-arm defense and biting. a Schematic illustration. The cockroaches often brought one or more legs up against the wasp and lodged the spines against the abdominal joint or along the abdomen, making it difficult for the wasp to sting. b Frame captured from a video showing the position of the midleg (red arrow) holding back the wasp's abdomen. See online supplementary Movie S4 for this and additional examples. c The cockroaches often raked the tibial spines repeatedly against the wasp during the struggle (red arrow), and occasionally lodged the spines in between the ab- dominal segments. This provided purchase for pushing the abdomen and stinger away from the thorax. See online supplementary Movie S5 for this and additional examples. d Frame captured from a video showing a cockroach attempting to bite the wasp's abdomen during the sting. In this case, the cockroach had lodged its spines between the abdominal segments and thus used its foreleg to bring the abdomen briefly between its mandibles; however, it was apparently unable to damage the smooth, hard cuticle. See online supplementary Movie S5 for this and other examples. and close inspection revealed a precarious situation for the wasp. The cockroach was able to lodge the spines of its forelimb under several of the wasp's abdominal segments and then drew its leg forward along with the wasp's abdomen. With its head turned and the jaws open, the cockroach managed to get the distal end of the wasp's abdomen briefly within its jaws (arrow in online suppl. Movie S5, clip 4). Apparently, it was unable to secure a hold with its mandibles on the smooth cuticle of the wasp. But the encounter, along with similar observations (online suppl. Movie S5, clip 5), highlights the potential risk. These frequent attempts to bite the wasp likely explain why the wasp holds its unused legs up and distant from the cockroach's head, presumably to keep them away from the jaws (Fig. 9). Finally, as reported by Fox et al. [2009], some cockroaches attempted to bite the wasp during the initial encounter (online suppl. Movie S5, clip 6). 


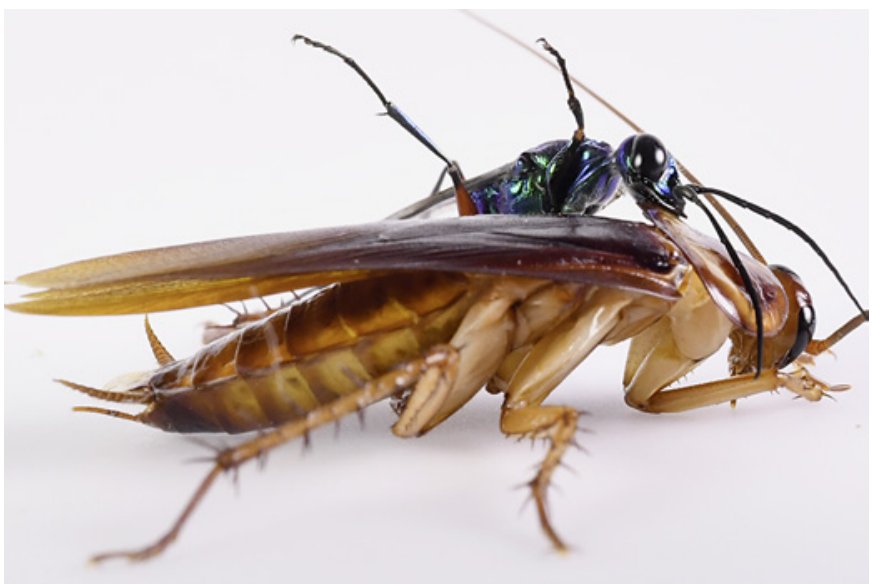

Fig. 9. Characteristic wasp posture during stinging. When delivering a sting, the wasps usually held their limbs up and away from the cockroach, in a pose reminiscent of a fencer. Presumably the similarity is in both form and function, as the wasp's delicate legs might otherwise be damaged by the cockroach's powerful jaws.

\section{Discussion}

Cockroaches and jewel wasps have been extensively studied to determine both general principles of neurobiology and unique aspects of predator-prey interactions. For example, cockroaches have been used to investigate how a signal is extracted from noise when mechanosensory cerci detect air movements, how air movement direction is coded by the activity of giant neurons, and how afferents innervating tibial spines code the stimulus strength over time [French and Kuster, 1981], to mention just a few contributions. Parasitoid jewel wasps are also a compelling study system by virtue of their unique venom and hunting strategies, which allow them to alter host behavior with a sting to the brain. Each system is useful for both basic science and teaching. For the latter, cockroaches are tractable for many student laboratories in neurobiology, whereas the ability of jewel wasps to "zombify" cockroaches provides a compelling framework for teaching about animal behavior, neurotransmitters, and the coevolution of parasitoids and their hosts.

But there is a gap of sorts in our understanding of how these two species interact. Specifically, the American cockroach is renowned to both neurobiologists and homeowners as an escape artist; yet the jewel wasp manages to sting this elusive target directly in the brain. How does the wasp manage to overcome the cockroach's escape mechanisms and potential defenses? This gap in our understanding is also a unique opportunity, because so much is already known about the biology of each species. Thus, new observations can be interpreted within the framework of numerous previous studies. And, in the spirit of the neuroethological approach, a more holistic understanding of the behavior of each species may be attained by considering how previously described mechanisms are put to use during a natural behavior - that is, what better way to study cockroach escape and defense than through the lens of a cockroach-hunting specialist?

The experimental approach was to examine these interactions in slow motion, often at high magnification, to reveal details that are simply impossible to observe in real time or with the naked eye. The main finding was that cockroaches have a suite of defensive behaviors that can be used to successfully defend themselves from hunting wasps. Some of these behaviors provide a context for previously studied components of the cockroach's sensory system (e.g., mechanosensory escape responses and tibial spine sensitivity), whereas others emphasize the utility of wasp behaviors (e.g., sting 1 paralyzes the front legs, thereby preventing the raking defense and stiff-arm block of the stinger during sting 2 in the throat). Before discussing the slow-motion, close-up interactions between the wasps and cockroaches, the efficacy of cockroach defenses is briefly recounted from the real-time trials.

\section{Efficacy of Cockroach Defenses}

One of the most obvious results is that many cockroaches put up a vigorous defense, and this greatly improved their likelihood of survival. Only $14 \%$ of the cockroaches that did not put up an initial defense (while being stalked) avoided sting 1 within the first $3 \mathrm{~min}$ of the encounter (sting 1 always led to sting 2 in the real-time trials, and thus was scored as a failed defense). The cockroaches that survived without an initial defense were able to remove the wasp from the pronotum before sting 1 by raking with tibial spines. Subsequently, either they managed to defend themselves or the wasp did not attack again. In contrast, $63 \%$ of the cockroaches that put up an initial defense (as indicated by stilt-standing) avoided sting 1 during the first $3 \mathrm{~min}$.

Moreover, in numerous trials, wasps that encountered a stilt-standing and kicking cockroach seemed to give up the attack. Online supplementary Movie S7 clips 1-5 show such examples. Often, the wasp was kicked multiple times in the head before it stopped stalking, suggesting the cockroach's behavior deterred the wasp. In addition, some of the cockroaches actually approached the wasp in a defensive posture (e.g., online suppl. Movie S7, clip 2), perhaps adding to the deterrent effect by signaling their 
fitness. For the purposes of this study, a time period of 3 min without a successful first sting was chosen to be scored as a successful defense, based on the premise that an uncontained, and unstung, cockroach in nature would eventually escape, particularly in cases during which the wasp gave up stalking for long intervals.

Of course, the cockroaches' defenses often failed. Thus, it is also informative to consider trials during which the cockroach put up a strong defense, but the wasp pressed the attack and succeeded. Online supplementary Movie S8 includes the full sequence for such a case. The $2 \mathrm{~min}$ 24 s interaction began with a stilt-standing cockroach that approached the wasp. The wasp in turn initially maintained its distance while continuously stalking the cockroach. The pronotum grasp was finally achieved when the wasp approached the right side of the cockroach - eliciting a defensive posture oriented to the right - but then circled around to grasp the pronotum on the left side. Note that, in this regard, the pronotum on the undefended side is usually angled toward the substrate (Fig. $2 \mathrm{~g}$ ), thus - in contrast to the defended side - providing a particularly easy target. Although the defense ultimately failed, as pointed out by Gross [1993] any increase in handling time can generally be considered beneficial to the host by providing more opportunities for escape.

\section{The Stilt-Standing Defense}

Stilt-standing was the hallmark of defensive behavior for the cockroaches. A review of the slow-motion interactions revealed many advantages provided by stilt-standing. A somewhat theoretical advantage was the maximization of the apparent body size, not only by raising the body but also by turning lengthwise - a common defensive strategy for prey attempting to deter a predator. But a more obvious advantage, specific to the jewel wasp attack, was raising the pronotum away from the wasp and angling it toward the far side. This makes the wasp's obligatory grasp on the horizontal edge of the pronotum much more difficult (e.g., Fig. 2g). In addition, stiltstanding was an apparent requirement for defensive kicking; no examples of kicking were observed in the absence of stilt-standing. This follows from the unusual style of the cockroach's kick, which can be contrasted with those of crickets and grasshoppers. Unlike the latter, cockroaches do not depend on the stereotypic pre-kick flexion of the tibia at the knee joint followed by explosive extension, which in turn makes use of the caudal or outer surface of the tibia for impact [Burrows and Wolf, 2002; Burrows and Morris, 2003]. Instead, in cockroaches, the tibia was extended at the knee joint as the entire hind leg was drawn forward and up and then swept down and back through the target. This movement likely requires the space between the limb and the substrate that is provided by stilt-standing.

However, there is another critical advantage provided by stilt-standing. The cockroach is essentially "on guard," with its antennae and tibial spines all positioned most favorably to detect the sudden lunge of an attacking predator. Note, in this regard, that Comer et al. [1994] have demonstrated short-latency, directional escape responses in $P$. americana in response to mechanosensory stimulation of the antennae, legs, and pronotum. In addition, their experiments have indicated that small predators (spiders) do not generate sufficient airborne cues to activate a cercal (wind-receptor) escape response, which has a latency too long to account for the escapes from wasp lunges described in the present study [Schaefer et al., 1994; Keasar et al., 2006]. The present results support their conclusions, as the high-magnification, slow-motion videos revealed multiple successful escapes that occurred just after an antenna or tibial spines were deflected by a lunging wasp. These observations, in turn, are a testament to the selection of a high-speed escape circuitry, since a delay of only a few milliseconds would have resulted in a successful wasp grasp in many of those trials (online suppl. Movie S2).

These results also highlight the utility of tibial spine mechanosensation, suggesting these organs play a key role in triggering escape responses (e.g., online suppl. Movie S2 and Fig. 5) and targeting defensive kicks (e.g., online suppl. Movie S1 and Fig. 4). The elicitation of either a kick or an escape response is no doubt determined by the spine deflection rate, and therefore may provide some behavioral context for recordings of spine-afferent responses. In addition, stilt-standing cockroaches often actively probed with their hind leg when being stalked by a wasp and made contact just prior to kicking (online suppl. Movie S1). This use of the hind limb for active touch is a further testament to the role of mechanosensation in the cockroach's defensive behaviors.

\section{Additional Defenses}

Once the wasp has successfully grasped the pronotum, the cockroach may still hold off the abdomen and dislodge the wasp with its tibial spines and continue to defend itself. In addition, the cockroach's tibial spines sometimes lodge between the wasp's abdominal segments during the struggle (Fig. 8). These observations highlight the critical utility (for the wasp) of sting 1 , which temporarily paralyzes the cockroach's front legs. It may be only 
with great difficulty, and perhaps at great risk, that the wasp could manage sting 2 into the cockroach's brain in the absence of sting 1, but after the wasp has stung the cockroach in the first thoracic ganglion, there is little hope of escape. Many cockroaches attempted to bite the wasp at this stage, but no evidence of damage to the wasp was observed in the present study. It seems likely that the smooth cuticle of the wasp's abdomen has been selected for resistance to this attack, as has been suggested for the tarantula hawk's cuticle, which seems generally impervious to the spider's fangs [Petrunkevitch, 1926].

\section{Conclusions}

The results of this investigation reveal many new details on interactions between cockroaches and their archenemy, the parasitoid jewel wasp. Many cockroaches detected the wasp as it approached, and they were able to mount a successful defense by stilt-standing and kicking, or by removing the wasp with an escape response combined with a raking defense with the tibial spines of the limbs. Although many studies have investigated the role of air movements for cockroaches' predator detection, the present study emphasized the importance of mechanosensation for cockroach defenses against relatively small attackers. Sudden contact with the tibial spines, pronotum, or antennae each resulted in short-latency es- cape responses, whereas probing contact by the wasp elicited violent kicking with the powerful, spiny hind limbs.

The results raise a number of interesting questions for further study. Are the defensive responses described here tailored to the jewel wasp's attack? Is there an arms race of sorts between the attacking jewel wasp and the defending cockroach? Do cockroaches exhibit a different suite of defenses against other specific predators? Or are jewel wasps acting as classic "rare predators" [Dawkins, 1982], able to overcome a single suite of generalized defenses that evolved in cockroaches in response to a wide range of predators? How does the short-latency escape response to tibial spine stimulation fit into the cockroach's neural circuitry [e.g., Ritzmann et al., 1991; Burdohan and Comer, 1996]? The accessibility of the cockroach as a study system may allow many of these questions to be addressed in future studies.

\section{Acknowledgements}

This work was supported by NSF grant 1456472 to K.C.C. Special thanks to Anita Manning and Steven Montgomery for collecting wasps for this research. Without their knowledge, help, and skill this research would not have been possible.

\section{Disclosure Statement}

The author has no conflict of interest to disclose.

\section{References}

Bell WJ, Sams GR (1973): Aggressiveness in the cockroach Periplaneta americana (Orthoptera, Blattidae). Behav Biol 9:581-593.

Burdohan JA, Comer CM (1996): Cellular organization of an antennal mechanosensory pathway in the cockroach, Periplaneta americana. J Neurosci 16:5830-5843.

Burrows M, Wolf H (2002): Jumping and kicking in the false stick insect Prosarthria teretrirostris: kinematics and motor control. J Exp Biol 205(pt 11):1519-1530.

Burrows M, Morris O (2003): Jumping and kicking in bush crickets. J Exp Biol 206(pt 6): 1035-1049.

Camhi JM (1984): Neuroethology: Nerve Cells and the Natural Behavior of Animals. Sunderland, Sinauer Associates Inc.

Camhi JM (1988): Escape behavior in the cockroach: distributed neural processing. Cell Mol Life Sci 44:401-408.
Camhi JM, Tom W (1978): The escape behavior of the cockroach Periplaneta americana. I. Turning response to wind puffs. J Comp Physiol 128:193-201.

Comer CM, Dowd JP (1993): Multisensory processing for movement: antennal and cercal mediation of escape turning in the cockroach; in Proceedings of the workshop on "Locomotion Control in Legged Invertebrates" on biological neural networks in invertebrate neuroethology and robotics. San Diego, Academic Press, pp 89-112.

Comer CM, Mara E, Murphy KA, Getman M, Mungy MC (1994): Multisensory control of escape in the cockroach Periplaneta americana. J Comp Physiol A 174:13-26.

Dawkins R (1982): The Extended Phenotype. Oxford, Oxford University Press, p 307.

Fouad K, Rathmayer W, Libersat F (1996): Neuromodulation of the escape behavior of the cockroach Periplaneta americana by the venom of the parasitic wasp Ampulex compressa. J Comp Physiol A 178:91-100.
Fox EG, Nascimento S, Eizemberg R (2009): Notes on the biology and behavior of the jewel wasp, Ampulex compressa (Fabricius, 1781) (Hymenoptera; Ampulicidae), in the laboratory, including first record of gregarious reproduction. Entomol News 120:430-437.

French AS, Kuster JE (1981): Sensory transduction in an insect mechnoreceptor: extended bandwidth measurements and sensitivity to stimulus strength. Biol Cybern 42:87-94.

Gal R, Kaiser M, Haspel G, Libersat F (2014): Sensory arsenal on the stinger of the parasitoid jewel wasp and its possible role in identifying cockroach brains. PLoS One 9:e89683.

Gal R, Libersat F (2008): A parasitoid wasp manipulates the drive for walking of its cockroach prey. Curr Biol 18:877-882.

Gal R, Libersat F (2010a): A wasp manipulates neuronal activity in the sub-esophageal ganglion to decrease the drive for walking in its cockroach prey. PLoS One 5:e10019. 
Gal R, Libersat F (2010b): On predatory wasps and zombie cockroaches: investigations of free will and spontaneous behavior in insects. Commun Integr Biol 3:458-461.

Gal R, Rosenberg LA, Libersat F (2005): Parasitoid wasp uses a venom cocktail injected into the brain to manipulate the behavior and metabolism of its cockroach prey. Arch Insect Biochem Physiol 60:198-208.

Gincel D, Haspel G, Libersat F (2004): Channelforming activity in the venom of the cockroach-hunting wasp, Ampulex compressa. Toxicon 43:721-727.

Gnatzy W, Heusslein R (1986): Digger wasps against crickets: I. Receptors involved in the antipredator strategies of the prey. Naturwissenschaften 73:212-215.

Gross P (1993): Insect behavioral and morphological defenses against parasitoids. Annu Rev Entomol 38:251-273.

Haspel G, Libersat F (2003): Wasp venom blocks central cholinergic synapses to induce transient paralysis in cockroach prey. J Neurobiol 54:628-637.

Haspel G, Rosenberg LA, Libersat F (2003): Direct injection of venom by a predatory wasp into cockroach brain. J Neurobiol 56:287-292.

Hustert R, Gnatzy W (1995): The motor program for defensive kicking in crickets: performance and neural control. J Exp Biol 198(pt 6):12751283.

Kaiser M, Libersat F (2015): The role of the cerebral ganglia in the venom-induced behavioral manipulation of cockroaches stung by the parasitoid jewel wasp. J Exp Biol 218(pt 7): 1022-1027.

Keasar T, Sheffer N, Glusman G, Libersat F (2006): Host-handling behavior: an innate component of foraging behavior in the parasitoid wasp Ampulex compressa. Ethology 112:699-706.
Libersat F (2003): Wasp uses venom cocktail to manipulate the behavior of its cockroach prey. J Comp Physiol A Neuroethol Sens Neural Behav Physiol 189:497-508.

Libersat F, Delago A, Gal R (2009): Manipulation of host behavior by parasitic insects and insect parasites. Annu Rev Entomol 54:189-207.

Libersat F, Gal R (2007): Neuro-manipulation of hosts by parasitoid wasps; in Rivers D, Yoder J (eds): Recent Advances in the Biochemistry, Toxicity and Mode of Action of Parasitic Wasp Venoms. Kerala, Research Signpost, pp 93-114.

Libersat F, Gal R (2013): What can parasitoid wasps teach us about decision-making in insects? J Exp Biol 216(pt 1):47-55.

Libersat F, Gal R (2014): Wasp voodoo rituals, venom-cocktails, and the zombification of cockroach hosts. Integr Comp Biol 54:129_ 142 .

Moore EL, Haspel G, Libersat F, Adams ME (2006): Parasitoid wasp sting: a cocktail of GABA, taurine, and $\beta$-alanine opens chloride channels for central synaptic block and transient paralysis of a cockroach host. J Neurobiol 66:811-820.

Nye SW, Ritzmann RE (1992): Motion analysis of leg joints associated with escape turns of the cockroach, Periplaneta americana. J Comp Physiol A 171:183-194.

Oakley B, Schafer R (1978): Experimental Neurobiology: A Laboratory Manual. Ann Arbor, University of Michigan Press.

Petrunkevitch A (1926): Tarantula versus tarantula-hawk: a study in instinct. J Exp Zool 45: 367-397.

Piek T, Visser JH, Veenendaal RL (1984): Change in behaviour of the cockroach, Periplaneta americana, after being stung by the sphecid wasp Ampulex compressa. Entomol Exp Appl 35:195-203.

Richardson BA, Paul RK (1993): Quantitative aspects of behaviour and reproduction in the Jewel wasp Ampulex compressa. Int Zoo Yearb 32:177-183.
Ritzmann RE (1984): The cockroach escape response; in Eaton RC (ed): Neural Mechanisms of Startle Behavior. Boston, Springer, pp 93 131.

Ritzmann RE (1993): The neural organization of cockroach escape and its role in context-dependent orientation; in Proceedings of the workshop on "Locomotion Control in Legged Invertebrates" on Biological neural networks in invertebrate neuroethology and robotics. San Diego, Academic Press, pp 113-137.

Ritzmann RE, Pollack AJ, Hudson SE, Hyvonen A (1991): Convergence of multi-modal sensory signals at thoracic interneurons of the escape system of the cockroach, Periplaneta americana. Brain Res 563:175-183.

Schaefer PL, Kondagunta GV, Ritzmann RE (1994): Motion analysis of escape movements evoked by tactile stimulation in the cockroach Periplaneta americana. J Exp Biol 190:287294.

Veltman J, Wilhelm W (1991): Husbandry and display of the Jewel wasp Ampulex compressa and its potential value in destroying cockroaches. Int Zoo Yearb 30:118-126.

Weisel-Eichler A, Haspel G, Libersat F (1999): Venom of a parasitoid wasp induces prolonged grooming in the cockroach. J Exp Biol 202(pt 8):957-964.

Weisel-Eichler A, Libersat F (2002): Are monoaminergic systems involved in the lethargy induced by a parasitoid wasp in the cockroach prey? J Comp Physiol A Neuroethol Sens Neural Behav Physiol 188:315-324.

Williams FX (1942): Ampulex compressa (Fabr.), a cockraoch-hunting wasp introduced from New Caledonia into Hawaii. Proc Hawaiian Entomol Soc 11:221-233.

Ye S, Leung V, Khan A, Baba Y, Comer CM (2003): The antennal system and cockroach evasive behavior. I. Roles for visual and mechanosensory cues in the response. J Comp Physiol A Neuroethol Sens Neural Behav Physiol 189:89-96. 